\title{
Efficacy of primary microvascular decompression versus subsequent microvascular decompression for trigeminal neuralgia
}

\author{
Debebe Theodros, BS, ${ }^{2}$ C. Rory Goodwin, MD, PhD, ${ }^{1}$ Matthew T. Bender, MD, ${ }^{1}$ Xin Zhou, MD, ${ }^{1}$ \\ Tomas Garzon-Muvdi, MD, MS, ${ }^{1}$ Rafael De la Garza-Ramos, MD, ${ }^{1}$ Nancy Abu-Bonsrah, BS, ${ }^{2}$ \\ Dimitrios Mathios, MD, ${ }^{1}$ Ari M. Blitz, MD, ${ }^{3}$ Alessandro Olivi, MD, ${ }^{1}$ Benjamin Carson, MD, ${ }^{1}$ \\ Chetan Bettegowda, MD, ${ }^{1}$ and Michael Lim, MD'1
}

${ }^{1}$ Department of Neurosurgery, ${ }^{2}$ The Johns Hopkins University School of Medicine, and ${ }^{3}$ Department of Radiology, The Johns Hopkins Hospital, Baltimore, Maryland

OBJECTIVE Trigeminal neuralgia (TN) is characterized by intermittent, paroxysmal, and lancinating pain along the distribution of the trigeminal nerve. Microvascular decompression (MVD) directly addresses compression of the trigeminal nerve. The purpose of this study was to determine whether patients undergoing MVD as their first surgical intervention experience greater pain control than patients who undergo subsequent MVD.

METHODS A retrospective review of patient records from 1998 to 2015 identified a total of 942 patients with TN and 500 patients who underwent MVD. After excluding several cases, 306 patients underwent MVD as their first surgical intervention and 175 patients underwent subsequent MVD. Demographics and clinicopathological data and outcomes were obtained for analysis.

RESULTS In patients who underwent subsequent MVD, surgical intervention was performed at an older age ( 55.22 vs 49.98 years old, $p<0.0001)$ and the duration of symptoms was greater $(7.22$ vs 4.45 years, $p<0.0001)$ than for patients in whom MVD was their first surgical intervention. Patients who underwent initial MVD had improved pain relief and no improvement in pain rates compared with those who had subsequent MVD $(95.8 \%$ and $4.2 \%$ vs $90.3 \%$ and $9.7 \%$, respectively, $p=0.0041$ ).

Patients who underwent initial MVD had significantly lower rates of facial numbness in the pre- and postoperative periods compared with patients who underwent subsequent MVD $(p<0.0001)$. The number of complications in both groups was similar $(p=0.4572)$.

CONCLUSIONS The results demonstrate that patients who underwent other procedures prior to MVD had less pain relief and a higher incidence of facial numbness despite rates of complications similar to patients who underwent MVD as their first surgical intervention.

https://thejns.org/doi/abs/10.3171/2016.5.JNS151692

KEY WORDS microvascular decompression; trigeminal neuralgia; pain

$\mathrm{T}$ RIGEMINAL neuralgia (TN) is a disorder characterized by intermittent, paroxysmal, lancinating pain along the distribution of the trigeminal nerve. Patients with TN suffer from intractable pain that can become refractory to medical management that prompts evaluation for surgical cure. Compression of the trigeminal nerve is the most

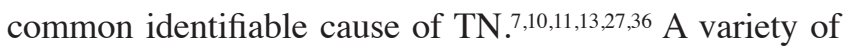
surgical options exist, which include minimally invasive procedures such as stereotactic radiosurgery (SRS), percutaneous procedures such as glycerol rhizotomy (GR), radiofrequency-thermocoagulation GR (RFTC-GR), and more invasive procedures such as microvascular decom-

ABBREVIATIONS CISS = constructive interference in steady-state; MVD = microvascular decompression; SRS = stereotactic radiosurgery; TN = trigeminal neuralgia SUBMITTED July 20, 2015. ACCEPTED May 4, 2016.

INCLUDE WHEN CITING Published online July 15, 2016; DOI: 10.3171/2016.5.JNS151692. 
pression (MVD). MVD aims to reverse the presumed etiology of TN via placement of a Teflon pledget between the compressed nerve and, most commonly, an overlying vascular structure. It is considered the gold standard surgical treatment for patients with medically intractable TN and demonstrable compression. . $^{15,26,31}$ Although MVD has been shown to exhibit the most durable outcomes, some patients elect to undergo less invasive procedures or are poor surgical candidates. ${ }^{16}$ Initial pain relief outcomes for patients undergoing MVD are excellent, ranging from $70 \%$ to $100 \%$ in multiple studies. $1,4,8,12,16,18,29,31,32,34,38 \mathrm{TN}$ patients commonly undergo multiple less invasive treatment options prior to MVD, but the effect of these prior surgical treatments on the efficacy of subsequent MVD has not been elucidated. Furthermore, few studies have compared the efficacy of MVD performed as first-line surgical intervention to MVD performed as a subsequent surgical intervention, nor has there been examination of factors associated with multiple interventions prior to MVD that predict outcomes.

We retrospectively analyzed demographic features, initial pain relief outcomes, durability of the results, complications, and vascular compression in patients undergoing an MVD performed as their first surgical intervention versus patients undergoing an MVD performed as a subsequent surgical intervention. We aimed to determine whether patients receiving an MVD as their initial intervention ("initial MVD") have better pain-related outcomes and/or reduced complications compared with patients undergoing an MVD as an intervention following other surgeries ("subsequent MVD").

\section{Methods}

\section{Patient Selection}

We retrospectively reviewed medical records of patients treated from 1998 to 2015 and identified a total of 942 patients with a diagnosis of TN, 500 of whom underwent MVD at our institution. Outcomes were available for 489 MVDs (98\%), and 5 MVDs (1\%) were excluded due to lack of follow-up. Of note, a subset of patients included in the analysis in this manuscript was reported on in a previous paper; ${ }^{9}$ however, we were addressing a different question. The diagnostic criterion for $\mathrm{TN}$ was pain in the distribution of the trigeminal nerve; pain that was intermittent, paroxysmal, shocklike, and lancinating in character; triggered by light touch; and responsive to TN medications. Idiopathic pain was described in 485 patients (97\%), and 4 (1\%) patients who experienced a component of constant, atypical pain were excluded. We also identified and excluded 1 patient with an epidermoid tumor causing compression (0.5\%), leaving 481 patients (98\%) for subsequent analysis. Of the 481 patients, 306 patients underwent MVD as their first surgical intervention and 175 patients underwent MVD as a subsequent surgical intervention. All patients who underwent subsequent MVD were included for analysis, regardless of the type of surgical intervention they first received. We defined prior interventions as GR, RFTC-GR, and SRS. Inclusion criteria are documented in Table 1. Our institutional review board approved this study.
TABLE 1. Inclusion criteria

\begin{tabular}{lcc}
\hline \multicolumn{1}{c}{ Condition } & No. & $\%$ \\
\hline Patients who underwent MVD & 500 & \\
\hline Patients w/ follow-up & 489 & 97.8 \\
\hline Patients w/ idiopathic TN & 485 & 97.0 \\
\hline Patients w/ idiopathic TN (MS \& cancer excluded) & 481 & 96.2 \\
\hline MVD as 1st intervention & 306 & 61.2 \\
\hline MVD as subsequent intervention & 175 & 35.0 \\
\hline
\end{tabular}

MS = multiple sclerosis

\section{Operative Technique}

Patients were positioned either in park-bench position or supine with a shoulder bump under the ipsilateral shoulder and the patient's head pinned in a Mayfield clamp, rotated $60^{\circ}$ toward the contralateral shoulder. Neuronavigation was used to identify the junction between the sigmoid sinus and transverse sinus over which a $5-\mathrm{cm}$ curvilinear skin incision was made. The Anspach drill was used to make a $3 \times 2-\mathrm{cm}$ retrosigmoid craniectomy. A cruciate dural opening was made and the arachnoid was incised to release CSF from the cisterna magna. The Leyla bar and Yaşargil retractor were positioned to gently retract the cerebellum medially. The microscope was brought in and the trigeminal nerve was visualized. The nerve was explored circumferentially to identify all possible arterial and venous sources of compression. Teflon pledgets were fluffed and positioned between the nerve and sources of compression to decompress the trigeminal nerve.

\section{Follow-Up and Data Collection}

Follow-up information was collected from outpatient records and surveys that were mailed to patients' homes to determine pain outcomes from surgical intervention, any pain recurrences, and any subsequent operations in both treatment groups. Follow-up surveys were used to gather information on postoperative outcomes and recurrence. The retrospective review of medical records included demographic information, medical history, TN symptomatology and medications, and the outcomes of prior surgical interventions.

Initial pain relief and hypesthesia for all patients was assessed at the first follow-up appointment, generally 2 weeks postoperatively. Pain relief outcomes were classified as follows: complete pain relief without TN medications, complete pain relief with TN medications, partial pain relief with or without medications, and no pain relief.

Postoperative numbness was assessed using the Barrow Neurological Institute Facial Hypesthesia Scale and Scoring System. According to this scale, a score of I indicates no facial numbness, II indicates mild facial numbness that is not bothersome, III indicates somewhat bothersome facial numbness, and IV indicates very bothersome facial numbness. The presence or absence of 13 relevant complications was recorded systematically.

\section{Statistical Analysis}

Statistical analysis was performed using Prism (GraphPad Software). Continuous variables are presented as 
means, standard deviations, or percentages and were analyzed using a one-tailed Student t-test. Categorical or binomial values were analyzed by Fisher exact chi-square test, with $p$ values less than 0.05 being considered statistically significant.

\section{Results \\ Patient Demographics}

Patient demographics are listed in Table 2. There were 216 female patients (71\%) who underwent MVD as their first surgical intervention versus 119 female patients $(68 \%)$ who underwent subsequent MVD. The mean age at intervention was 49.98 years for patients who underwent initial MVD and 55.22 years for patients who underwent subsequent MVD ( $\mathrm{p}<0.0001)$. The mean TN symptom duration average was 4.44 years versus 7.22 years for patients who underwent initial MVD versus subsequent MVD, respectively ( $\mathrm{p}<0.0001)$. The ratio of left-sided symptoms to right-sided symptoms was $0.42: 0.58$ versus $0.42: 0.58$ for patients who underwent initial MVD versus patients who underwent subsequent MVD, respectively. There were $21(7 \%)$ patients in the initial MVD group who experienced bilateral symptoms compared with $13(7 \%)$ in the subsequent MVD group. The distribution of symptoms involved 1 nerve (V1, V2, or V3) alone in 96 patients (31\%) who underwent initial MVD versus in 60 patients (34\%) who underwent subsequent MVD. The distribution of symptoms involved any combination of 2 nerves (V1 and V2, V1 and V3, or V2 and V3) in 135 patients (44\%) who underwent initial MVD versus $69(39 \%)$ in patients who underwent subsequent MVD. Lastly, the distribution of symptoms involved all nerve divisions (V1-V3) in 75 patients $(16 \%)$ who underwent initial MVD versus 46 patients $(23 \%)$ who underwent subsequent MVD. Of note, the number of female patients, side of $\mathrm{TN}$ pain, unilateral and bilateral TN symptom percentage, and distribution of TN pain were well matched between the 2 groups. As previously stated, there were significant differences in mean age at surgery $(\mathrm{p}<0.0001)$ and TN symptom duration $(\mathrm{p}<$ $0.001)$ between the groups.

\section{Pain Relief}

Pain relief outcomes are documented in Table 3. A total of 224 cases $(73 \%)$ in which MVD was the first surgical intervention and $120(69 \%)$ in which it was a subsequent surgical intervention resulted in pain-free status without medications. In 29 (10\%) initial MVD interventions and $15(9 \%)$ subsequent MVD interventions, patients reported being pain free but still on medications. In 40 (13\%) cases in which MVD was the first surgical intervention and in $23(13 \%)$ cases in which it was a subsequent procedure, patients reported an improvement in TN pain. Finally, in $13(4 \%)$ cases in which MVD was the first surgical intervention and $17(10 \%)$ cases in which it was a subsequent surgical procedure, patients reported no improvement in TN pain. Among patients who underwent MVD as their first surgical intervention, $95.8 \%$ of patients experienced some pain relief whereas among those who underwent MVD as a subsequent intervention, 90.3\% reported some pain relief $(\mathrm{p}=0.0041)$.
TABLE 2. Patient demographics*

\begin{tabular}{|c|c|c|c|c|}
\hline Variable & $\begin{array}{l}\text { 1st Surgical } \\
\text { Intervention }\end{array}$ & $\begin{array}{l}\text { Subsequent } \\
\text { Surgical } \\
\text { Intervention }\end{array}$ & Total & $p$ Value \\
\hline Patients & 306 & 175 & 482 & \\
\hline $\begin{array}{l}\text { No. of female pa- } \\
\text { tients }\end{array}$ & 216 & 119 & 336 & \\
\hline Mean age (yrs) & $49.98 \pm 12.17$ & $55.22 \pm 13.36$ & & $<0.0001$ \\
\hline $\begin{array}{l}\text { Mean TN symptom } \\
\text { duration (yrs) }\end{array}$ & $4.448 \pm 4.303$ & $7.224 \pm 5.491$ & & $<0.0001$ \\
\hline Side (It/rt ratio) & $0.42: 0.58$ & $0.42: 0.58$ & & \\
\hline Unilat TN symptoms & 285 & 162 & & \\
\hline \multicolumn{5}{|l|}{ Distribution } \\
\hline $\mathrm{V} 1$ & 12 & 10 & 22 & \\
\hline V2 & 34 & 18 & 52 & \\
\hline V3 & 50 & 32 & 82 & \\
\hline V1 \& V2 & 45 & 31 & 86 & \\
\hline V1 \& V3 & 5 & 5 & 10 & \\
\hline V2 \& V3 & 85 & 33 & 118 & \\
\hline V1-V3 & 75 & 46 & 121 & \\
\hline Any V1 & 62 & 46 & & \\
\hline Any V2 & 164 & 82 & & \\
\hline Any V3 & 210 & 111 & & \\
\hline
\end{tabular}

* Mean values are presented \pm SD.

\section{Sensory Changes}

Preoperative and postoperative sensory changes are documented in Table 4. Patients who underwent initial MVD experienced negligible sensory changes, but patients who underwent subsequent MVD experienced an increase in sensory loss postoperatively. For procedures in which MVD was the first surgical intervention, 93\% of patients before and $85 \%$ of patients after surgery experienced intact facial sensation with no facial numbness. For procedures in which MVD was a subsequent surgical intervention, $77 \%$ of patients before and $65 \%$ of patients after surgery experienced no facial numbness. A higher number of patients reported no facial numbness before their operation if MVD was their first surgical intervention ( $\mathrm{p}<0.0001)$. Similarly, patients in whom MVD was the initial surgical intervention were found to have a higher rate of preserved facial sensation postoperatively compared with those in whom MVD was a subsequent surgical intervention $(\mathrm{p}<0.0001)$.

\section{Complications}

Complications are documented in Table 5. In procedures in which MVD was the first surgical intervention, complications included dysesthesia (1 case [1\%]), paresthesia ( 1 case $[0.3 \%]$ ), meningitis ( 3 cases [1.0\%], hemifacial spasm ( 1 case $[0.3 \%])$, hearing loss (5 cases $[1.6 \%])$, facial palsy (3 cases [1.0\%]), and CSF leak (4 cases [1.3\%]). In procedures in which MVD was a subsequent surgical intervention, complications included paresthesia (3 cases [2\%]), herpes simplex virus reaction (1 case [1\%]), corneal anesthesia (2 cases [1\%]), hearing loss (2 cases [1\%]), cra- 
TABLE 3. Initial pain relief outcomes

\begin{tabular}{lcrrrrrr}
\hline \multicolumn{1}{c}{ Outcome } & 1st Surgical Intervention & $\%$ & Subsequent Surgical Intervention & $\%$ & Total & Overall \% & $p$ Value \\
\hline No pain, no meds & 224 & 73.2 & 120 & 68.6 & 344 & 71.52 & 0.0041 \\
\hline No pain w/ meds & 29 & 9.5 & 15 & 8.6 & 44 & 9.15 & \\
\hline Pain improved & 40 & 13.1 & 23 & 13.1 & 63 & 13.09 \\
\hline Pain unchanged & 13 & 4.2 & 17 & 9.7 & 30 & 6.24 \\
\hline Total & 306 & 100 & 175 & 100 & 481 & 100 \\
\hline
\end{tabular}

Med = medication

nial nerve VI palsy (1 case [1\%]), and facial palsy (2 cases [1\%]). There was no difference in complication rates between groups $(\mathrm{p}=0.4572)$. The mortality rate during the immediate postoperative period was $0 \%$ for both groups.

\section{Discussion}

MVD has been shown to be the only surgical treatment that directly treats the proposed etiology of TN. It is relatively safe, and the number of procedures performed in the United States rose by 194\% between 1988 and 2008.,328,37 Additionally, MVD has been shown to have higher rates of TN pain relief in the elderly. ${ }^{6,21,33}$ However, it is an invasive procedure and not without certain risks, although these risks have been shown to be independent of age. ${ }^{23}$ We retrospectively analyzed the clinical outcomes of 481 patients, in whom MVD was either the first or a subsequent surgical intervention after less invasive procedures. In patients who underwent a subsequent MVD, we documented a lower rate of pain relief compared with patients who underwent an initial MVD. Additionally, patients who underwent MVD as their first surgical intervention experienced lower rates of facial numbness in the preoperative and postoperative period. The rates of complications in both groups were similar, and there were no deaths in our series.

Sindou et al. documented complete pain relief in $77 \%$ of patients over a follow-up period that ranged from 3 to 20 years. ${ }^{30}$ As mentioned, the rate of initial pain relief after MVD has been shown to vary from $70 \%$ to $100 \%$ in patients treated for TN. ${ }^{1,4,8,12,16,18,29,31,32,34,38}$ In the largest series, Barker et al. reported the results of 1204 MVDs with immediate, 1-year, and 10-year complete pain relief achieved in $82 \%, 80 \%$, and $70 \%$ of procedures, respective$1 y .{ }^{4}$ Sindou et al. reported that $73.3 \%$ of patients were free of pain at 15 years. ${ }^{31}$ Furthermore, Bederson and Wilson reported a recurrence rate of $2 \%$ per year, while Barker et al. reported annual recurrence rates of $<2 \%$ and $<1 \%$ at 5 and 10 years, respectively. ${ }^{4,5}$ Similar to these studies, we observed the rates of complete pain relief and any pain relief of $73.2 \%$ and $95.8 \%$, respectively, in the initial MVD group and $68.6 \%$ and $90.3 \%$, respectively, in the subsequent MVD group.

MVD has the potential to alter facial sensations in a variety of ways, and, interestingly, at baseline, somatosensory perception may be altered in patients with $\mathrm{TN}$. Miles et al. demonstrated decreased tactile sensation in asymptomatic nerve distributions on patients' symptomatic side preoperatively $(\mathrm{p}=0.006)$. Using the contralateral division as a control, they reported that by 6 months after surgery, patients had no difference in perception of touch, as well as coolness, the latter being less significant. They also demonstrated a significant difference between pinprick sensation on the symptomatic side and the asymptomatic side that resolved at the 12-month postoperative time point. Last, among patients whose TN affected the maxillary division, the skin temperature on the symptomatic side was $0.6^{\circ} \mathrm{C}$ lower than that on the asymptomatic

TABLE 4. Preoperative and postoperative hypesthesia measured using the Barrow Neurological Institute Facial Hypesthesia Scale and Scoring System

\begin{tabular}{crrrrrrr}
\hline BNI Score & 1st Surgical Intervention & $\%$ & Subsequent Surgical Intervention & $\%$ & Total & Overall \% & $p$ Value \\
\hline Preop & & & & & & & \\
\hline 1 & 283 & 92.5 & 135 & 75.1 & 418 & 86.9 & $<0.0001$ \\
\hline 2 & 22 & 7.2 & 2 & 20.0 & 57 & 11.9 & \\
\hline 3 & 1 & 0.3 & 3 & 1.2 & 3 & 0.6 & \\
\hline 4 & 0 & 0 & 175 & 1.7 & 3 & 0.6 & \\
\hline Total & 306 & 100 & & 100 & 481 & 100 & \\
\hline Postop & & & 113 & 64.6 & 372 & 77.3 & $<0.0001$ \\
\hline 1 & 259 & 84.7 & 55 & 31.4 & 100 & 20.8 & \\
\hline 2 & 45 & 14.7 & 5 & 2.9 & 6 & 1.3 & \\
\hline 3 & 1 & 0.3 & 2 & 1.1 & 3 & 0.6 & \\
\hline 4 & 1 & 0.3 & 175 & 100 & 481 & 100 \\
\hline Total & 306 & 100 & & & & \\
\hline
\end{tabular}

$\mathrm{BNI}=$ Barrow Neurological Institute. 
TABLE 5. Summary of complications

\begin{tabular}{|c|c|c|c|c|c|c|}
\hline Complication & $\begin{array}{l}\text { 1st Surgical } \\
\text { Intervention }\end{array}$ & $\%$ & $\begin{array}{l}\text { Subsequent } \\
\text { Surgical } \\
\text { Intervention }\end{array}$ & $\%$ & Total & $\begin{array}{c}\text { Overall } \\
\%\end{array}$ \\
\hline Dysesthesia & 3 & 1.0 & 0 & 0 & 3 & 0.6 \\
\hline Paresthesia & 1 & 0.3 & 3 & 1.7 & 4 & 0.8 \\
\hline HSV reaction & 0 & 0 & 1 & 0.6 & 1 & 0.2 \\
\hline $\begin{array}{l}\text { Corneal anes- } \\
\text { thesia }\end{array}$ & 0 & 0 & 2 & 1.1 & 2 & 0.4 \\
\hline $\begin{array}{r}\text { Anesthesia } \\
\text { dolorosa }\end{array}$ & 0 & 0 & 0 & 0 & 0 & 0 \\
\hline $\begin{array}{l}\text { Masseter weak- } \\
\text { ness }\end{array}$ & 0 & 0 & 0 & 0 & 0 & 0 \\
\hline TMJ dysfunction & 0 & 0 & 0 & 0 & 0 & 0 \\
\hline Hematoma & 0 & 0 & 0 & 0 & 0 & 0 \\
\hline Meningitis & 3 & 1.0 & 0 & 0 & 3 & 0.6 \\
\hline $\begin{array}{l}\text { Hemifacial } \\
\text { spasm }\end{array}$ & 1 & 0.3 & 0 & 0 & 1 & 0.4 \\
\hline Hearing loss & 5 & 1.6 & 2 & 1.1 & 6 & 1.2 \\
\hline VI nerve palsy & 0 & 0 & 1 & 0.6 & 1 & 0.2 \\
\hline Facial palsy & 3 & 1.0 & 2 & 1.1 & 5 & 1.0 \\
\hline CSF leak & 4 & 1.3 & 0 & 0 & 4 & 0.8 \\
\hline
\end{tabular}

HSV = herpes simplex virus; $\mathrm{TMJ}=$ temporomandibular joint.

side preoperatively. ${ }^{22}$ Hypesthesia can affect up to $37 \%$ of cases, while facial numbness may occur in 1.6\%-17.3\% of patients. ${ }^{3,4,15}$ Of note, postoperative facial numbness has been shown to predict facial burning and aching and be a predictor of worse outcomes $(p=0.03) .{ }^{3}$ Our study demonstrated a slight increase in reported facial numbness in both cohorts of patients after MVD. Furthermore, the number of patients with no facial numbness versus any numbness before and after MVD among patients who underwent an initial vs a subsequent MVD was significant $(\mathrm{p}<0.0001)$.

CSF leak occurs in $0.8 \%-3.2 \%$ of patients. ${ }^{4,15,19}$ Rates of hearing loss are reported to range between $0.97 \%$ and $3.0 \% .^{24,28}$ In one of the largest MVD series for TN to date, McLaughlin et al. demonstrated the risk of cerebellar injury to be $0.68 \% .^{20}$ Dysesthesia has been reported as a complication and may occur in as few as $0.3 \%$ of patients. In our study, we found that patients who underwent MVD as a subsequent intervention had rates of complications similar to those who underwent MVD as their first surgical intervention. However, it should be noted that the total number of complications was higher in patients who underwent MVD as a primary, rather than subsequent, surgical intervention. It is important to realize that although this potential difference may not be statistically significant, patients who undergo MVD as an initial surgical intervention may indeed experience higher rates of complications.

Various attempts have been made to identify the patient population most likely to benefit from MVD for the treatment of TN. Key patient and disease characteristics have been shown to predict better outcomes and a lower likelihood of recurrence. Jo et al. performed a retrospec- tive study to establish such characteristics and were able to identify patient age $<70$ years, high severity of contact/compression, and single-vessel compression as being correlated with better outcomes. Additionally, their group found a positive correlation between preoperative neuroimaging features and neurovascular compression, specifically the presence of the "CSF rim" sign, defined as a narrow CSF signal between the nerve and the vessel on axial constructive interference in steady-state (CISS) imaging, as well as the "deviation" sign, which was defined as deviation on horizontal compression also identified on axial CISS. ${ }^{14}$ Zhang et al. also attempted to identify prognostic factors for patients undergoing MVD for the treatment of TN. Their group identified typical symptoms, preoperative MRI findings, and intraoperative findings of vessel compression as prognostic factors suggestive of an excellent outcome. ${ }^{38}$ Finally, Barker et al. identified 4 factors predicting long-term relief: immediate postoperative pain relief, male sex, absence of venous compression, and preoperative symptom duration greater than 8 years. ${ }^{4}$

Multiple risk factors for TN recurrence in patients undergoing MVD exist. Some studies have shown female sex as a risk factor for recurrent TN, while others have shown evidence to the contrary. ${ }^{12,17,21,35}$ Greater time from symptom onset to treatment has also been identified as a risk factor for recurrence after MVD. ${ }^{2,5}$ The nature of the pain has also shown to be a poor prognostic factor after surgery. Szapiro et al. reported a $95 \%$ cure rate in patients with paroxysmal pain versus a $58 \%$ cure rate in patients with paroxysmal and permanent pain, which was statistically significant $(\mathrm{p}<0.001)$. Furthermore, among patients with permanent pain, those with pain involving 2 or more divisions fared worse after MVD than patients whose pain involved only 1 division. ${ }^{34}$ Finally, the presence of compression has been shown to be associated with lower rates of recurrence compared with the absence of compression. ${ }^{6,21,25}$ Interestingly, Barba and Alksne reported that prior destructive surgery was a prognostic factor for poor outcome in patients undergoing MVD $(\mathrm{p}<0.005){ }^{2}$ Barker et al. reported 4 factors that predicted higher rates of recurrence, which were female sex, preoperative symptom duration $>8$ years, venous compression, and lack of immediate postoperative pain relief. ${ }^{4}$

Inherent to our study are several limitations. Although multiple studies have revealed that duration of symptoms is a reliable predictor of outcome, numerous variables may also influence outcomes. Data pertaining to these variables-for example, vascular compression, sex, and TN pain-were collected in our series and may also independently influence surgical outcomes., ${ }^{2,5}$ Multiple surgeons performed the MVD procedure, and, as a result, there is likely a small difference in interoperator variability. However, this potential operator variability difference did not manifest in complication rates, as the rates of complications were similar in both groups. This may have manifested as some surgeons offering MVD to different-age patient populations, as well as with different pain outcomes. Furthermore, the patient population at our tertiary-care center is unique and represents patients who may have self-selected for MVD. Another limitation lies in the retrospective nature of the study and the descriptive 
nature of facial numbness. No objective definition/measures aside from patient self-reports exist with regard to numbness, and this represents an inherent limitation to the BNI hypesthesia scale. Last, pain outcomes were not classified objectively but rather based on patient self-reports with results interpreted through the context of a standardized pain outcome scoring system.

Our findings suggest that patients with typical TN pain who undergo MVD as their first surgical intervention may experience better pain outcomes than patients who undergo MVD that has been preceded by other surgical interventions. Although MVD results in excellent pain relief outcomes, some patients' pain recurs, and it is important to inform patients that lower success rates are associated with subsequent surgical interventions. Future studies must delineate the role of specific prior surgical interventions, such prior MVD, SRS, GR, or RFTC-GR, as well as sources of compression, on pain outcome. Additionally, future studies should investigate whether the number of prior interventions influences the clinical outcomes associated with future operations.

\section{Conclusions}

MVD is the only surgical treatment aimed at a definitive cause for TN. This study reports patient demographics, pain outcomes, complication rates, facial sensation changes, and time to recurrence for patients undergoing MVD as their first surgical intervention versus MVD as a subsequent surgical intervention; we found a rather robust response to MVD whether it is the first surgical intervention to treat $\mathrm{TN}$ or whether it is a subsequent operation. Additionally, our low complication rates and $0 \%$ mortality rate suggest that MVD is a safe and effective procedure for patients suffering from TN.

\section{References}

1. Apfelbaum RI: A comparison of percutaneous radiofrequency trigeminal neurolysis and microvascular decompression of the trigeminal nerve for the treatment of tic douloureux. Neurosurgery 1:16-21, 1977

2. Barba D, Alksne JF: Success of microvascular decompression with and without prior surgical therapy for trigeminal neuralgia. J Neurosurg 60:104-107, 1984

3. Barker FG II, Jannetta PJ, Bissonette DJ, Jho HD: Trigeminal numbness and tic relief after microvascular decompression for typical trigeminal neuralgia. Neurosurgery 40:39-45, 1997

4. Barker FG II, Jannetta PJ, Bissonette DJ, Larkins MV, Jho HD: The long-term outcome of microvascular decompression for trigeminal neuralgia. N Engl J Med 334:1077-1083, 1996

5. Bederson JB, Wilson CB: Evaluation of microvascular decompression and partial sensory rhizotomy in 252 cases of trigeminal neuralgia. J Neurosurg 71:359-367, 1989

6. Burchiel KJ, Clarke H, Haglund M, Loeser JD: Long-term efficacy of microvascular decompression in trigeminal neuralgia. J Neurosurg 69:35-38, 1988

7. Chakraborty A, Bavetta S, Leach J, Kitchen N: Trigeminal neuralgia presenting as Chiari I malformation. Minim Invasive Neurosurg 46:47-49, 2003

8. Dahle L, von Essen C, Kourtopoulos H, Ridderheim PA, Vavruch L: Microvascular decompression for trigeminal neuralgia. Acta Neurochir (Wien) 99:109-112, 1989
9. Eseonu CI, Goodwin CR, Zhou X, Theodros D, Bender MT, Mathios D, et al: Reduced CSF leak in complete calvarial reconstructions of microvascular decompression craniectomies using calcium phosphate cement. J Neurosurg 123:14761479,2015

10. Haines SJ, Jannetta PJ, Zorub DS: Microvascular relations of the trigeminal nerve. An anatomical study with clinical correlation. J Neurosurg 52:381-386, 1980

11. Hamlyn PJ, King TT: Neurovascular compression in trigeminal neuralgia: a clinical and anatomical study. J Neurosurg 76:948-954, 1992

12. Haridas A, Mathewson C, Eljamel S: Long-term results of 405 refractory trigeminal neuralgia surgeries in 256 patients. Zentralbl Neurochir 69:170-174, 2008

13. Jannetta PJ: Arterial compression of the trigeminal nerve at the pons in patients with trigeminal neuralgia. J Neurosurg 26 (1 Suppl):159-162, 1967

14. Jo KW, Kong DS, Hong KS, Lee JA, Park K: Long-term prognostic factors for microvascular decompression for trigeminal neuralgia. J Clin Neurosci 20:440-445, 2013

15. Kabatas S, Albayrak SB, Cansever T, Hepgul KT: Microvascular decompression as a surgical management for trigeminal neuralgia: a critical review of the literature. Neurol India 57:134-138, 2009

16. Klun B: Microvascular decompression and partial sensory rhizotomy in the treatment of trigeminal neuralgia: personal experience with 220 patients. Neurosurgery 30:49-52, 1992

17. Kolluri S, Heros RC: Microvascular decompression for trigeminal neuralgia. A five-year follow-up study. Surg Neurol 22:235-240, 1984

18. Lee KH, Chang JW, Park YG, Chung SS: Microvascular decompression and percutaneous rhizotomy in trigeminal neuralgia. Stereotact Funct Neurosurg 68:196-199, 1997

19. Lee SH, Levy EI, Scarrow AM, Kassam A, Jannetta PJ: Recurrent trigeminal neuralgia attributable to veins after microvascular decompression. Neurosurgery 46:356-362, 2000

20. McLaughlin MR, Jannetta PJ, Clyde BL, Subach BR, Comey $\mathrm{CH}$, Resnick DK: Microvascular decompression of cranial nerves: lessons learned after 4400 operations. J Neurosurg 90:1-8, 1999

21. Mendoza N, Illingworth RD: Trigeminal neuralgia treated by microvascular decompression: a long-term follow-up study. Br J Neurosurg 9:13-19, 1995

22. Miles JB, Eldridge PR, Haggett CE, Bowsher D: Sensory effects of microvascular decompression in trigeminal neuralgia. J Neurosurg 86:193-196, 1997

23. Ogungbo BI, Kelly P, Kane PJ, Nath FP: Microvascular decompression for trigeminal neuralgia: report of outcome in patients over 65 years of age. Br J Neurosurg 14:23-27, 2000

24. Olson S, Atkinson L, Weidmann M: Microvascular decompression for trigeminal neuralgia: recurrences and complications. J Clin Neurosci 12:787-789, 2005

25. Piatt JH Jr, Wilkins RH: Treatment of tic douloureux and hemifacial spasm by posterior fossa exploration: therapeutic implications of various neurovascular relationships. Neurosurgery 14:462-471, 1984

26. Pollock BE, Schoeberl KA: Prospective comparison of posterior fossa exploration and stereotactic radiosurgery dorsal root entry zone target as primary surgery for patients with idiopathic trigeminal neuralgia. Neurosurgery 67:633-639, 2010

27. Rozen TD: Trigeminal neuralgia and glossopharyngeal neuralgia. Neurol Clin 22:185-206, 2004

28. Shakur SF, Bhansali A, Mian AY, Rosseau GL: Neurosurgical treatment of trigeminal neuralgia. Dis Mon 57:570-582, 2011

29. Shibahashi K, Morita A, Kimura T: Surgical results of microvascular decompression procedures and patient's postoper- 
ative quality of life: review of 139 cases. Neurol Med Chir (Tokyo) 53:360-364, 2013

30. Sindou M, Howeidy T, Acevedo G: Anatomical observations during microvascular decompression for idiopathic trigeminal neuralgia (with correlations between topography of pain and site of the neurovascular conflict). Prospective study in a series of 579 patients. Acta Neurochir (Wien) 144:1-13, 2002

31. Sindou M, Leston J, Decullier E, Chapuis F: Microvascular decompression for primary trigeminal neuralgia: long-term effectiveness and prognostic factors in a series of 362 consecutive patients with clear-cut neurovascular conflicts who underwent pure decompression. J Neurosurg 107:1144-1153, 2007

32. Steiger HJ: Prognostic factors in the treatment of trigeminal neuralgia. Analysis of a differential therapeutic approach. Acta Neurochir (Wien) 113:11-17, 1991

33. Sun T, Saito S, Nakai O, Ando T: Long-term results of microvascular decompression for trigeminal neuralgia with reference to probability of recurrence. Acta Neurochir (Wien) 126:144-148, 1994

34. Szapiro J Jr, Sindou M, Szapiro J: Prognostic factors in microvascular decompression for trigeminal neuralgia. Neurosurgery 17:920-929, 1985

35. Theodosopoulos PV, Marco E, Applebury C, Lamborn KR, Wilson CB: Predictive model for pain recurrence after posterior fossa surgery for trigeminal neuralgia. Arch Neurol 59:1297-1302, 2002

36. van Kleef M, van Genderen WE, Narouze S, Nurmikko TJ, van Zundert J, Geurts JW, et al: 1. Trigeminal neuralgia. Pain Pract 9:252-259, 2009

37. Wang DD, Ouyang D, Englot DJ, Rolston JD, Molinaro AM, Ward M, et al: Trends in surgical treatment for trigeminal neuralgia in the United States of America from 1988 to 2008 J Clin Neurosci 20:1538-1545, 2013

38. Zhang H, Lei D, You C, Mao BY, Wu B, Fang Y: The long- term outcome predictors of pure microvascular decompression for primary trigeminal neuralgia. World Neurosurg 79:756-762, 2013

\section{Disclosures}

Dr. Michael Lim is a consultant for Stryker. Dr. Goodwin is a UNCF Merck Postdoctoral Fellow and has received an award from the Burroughs Wellcome Fund. This article reflects the views of the authors and should not be construed to represent the FDA's views or policies.

\section{Author Contributions}

Conception and design: Lim, Theodros, Blitz. Acquisition of data: Theodros, Bender, Zhou, Abu-Bonsrah. Analysis and interpretation of data: Lim, Theodros, Carson, Bettegowda. Drafting the article: Theodros. Critically revising the article: Lim, Theodros, Goodwin, Garzon-Muvdi, Mathios, Blitz, Olivi, Carson, Bettegowda. Reviewed submitted version of manuscript: Theodros, Goodwin, Bender, Zhou, Abu-Bonsrah, Mathios, Blitz, Carson, Bettegowda. Statistical analysis: Goodwin, Garzon-Muvdi, De la Garza Ramos. Administrative/technical/material support: Carson, Bettegowda.

\section{Supplemental Information}

Previous Presentations

Portions of this work were presented in abstract form at the Annual Meeting of the American Association of Neurological Surgeons, May 2-6, 2015, Washington, DC.

\section{Correspondence}

Michael Lim, Department of Neurosurgery, Johns Hopkins Hospital, 600 N Wolfe St., Phipps 123, Baltimore, MD 21287. email: mlim3@jhmi.edu. 